\title{
COMPARATIVE ANALYSIS BETWEEN THE THEORIES OF ROAD TRANSPORT SAFETY AND EMISSION
}

\author{
Ádám Török \\ Dept of Transport Economics, Budapest University of Technology and Economics, Hungary \\ Submitted 10 December 2014; resubmitted 24 February 2015; accepted 20 April 2015; \\ first published online 13 July 2015
}

\begin{abstract}
In this paper, author's aim is to investigate the tendencies of EU27 countries based on road transport safety and road transport-related $\mathrm{CO}_{2}$ emission. On EU level huge efforts have been made in order to reduce the number of fatal road accidents and to reduce the $\mathrm{CO}_{2}$ emission as well. There is a strong revealed driving force behind the connection of road fatalities and social mortalities. The main research question is if there is such a tendency behind the time-series of road transport-related $\mathrm{CO}_{2}$ reduction? Author has used the tools of mathematical statistics in order to investigate the phenomena and to reveal the interdependencies.
\end{abstract}

Keywords: traffic safety; environmental impact; road accident; socio-economic characteristics; statistical analysis.

\section{Introduction}

World Health Organization (WHO) has warned that traffic accidents are on a path to becoming the fifth leading cause of premature mortality worldwide by 2030 . Traditionally, road safety policies aim to reduce the likelihood of a crash by improving road infrastructure, by educating road users, and to reduce the severity of a crash by improving vehicle technology and enforcing seatbelt and helmet laws. Equally important should be a focus on the promotion of safer modes, such as public transit, and by reducing exposure. Cities and regions with less vehicle travel have lower rates of crashes and fatalities (Kenworthy et al. 1997; Bhalla et al. 2007; Shen et al. 2013). Cities with high transit mode shares tend to have lower citywide traffic fatality rates. Sustainable urban form (e.g. higher density, better street connectivity that allow for lower speed) can also improve road safety (Dumbaugh, Rae 2009). Road safety concerns all EU citizens. Using the roads and streets is part of the everyday life, but each year almost 30000 lives are lost on these roads. This is an unacceptably high price to pay. In addition, the road accidents cause real socio-economic costs of around 2\% of EU GDP every year. The responsibility is shared, primarily between the road users, the vehicle manufacturers, the infrastructure managers, the local and national authorities and the EU. Therefore huge effort has been made since 1994 for the decrease of fatal road accidents. In the recent years huge amount of energy, time and money has been spent, a lot of measures have been done in order to reduce the number of fatal accidents. There is a strong revealed economic connection between road transport fatalities and social mortalities.

The EU 27's greenhouse gas (GHG) emissions that related to transport as well as road fatal accidents have been increasing and are projected to continue to do so. In addition, lot has been done in this topic to reduce transport-related GHG emission (Hilmola 2013). Population (number of inhabitants), road vehicle (passenger car unit), road transport safety (number of fatal road accidents) and emission $\left(\mathrm{CO}_{2}\right)$ has been analysed on a yearly base from 2000 to 2009 in order to reveal the tendencies and seek for the interdependencies. There is a strong revealed driving force behind the connection of road fatalities and social mortalities. The main research question is if there is such a tendency behind the timeseries of road transport-related $\mathrm{CO}_{2}$ reduction? As currently in road transport the $\mathrm{CO}, \mathrm{HC}, \mathrm{NO}_{\mathrm{x}}$, emission is standardised with more and more rigorous standards by UNECE (EURO standards for road vehicles) therefore the European Union makes extra efforts on decreasing the $\mathrm{CO}_{2}$ emission that is not yet standardised. Therefore, hidden economical drivers of $\mathrm{CO}_{2}$ emission were sought. 


\section{Methodology - Comparison of Time Series}

As the basic were four independent time series of social mortality rate, of road transport fatality rate, social emission rate and road transport-related emission rate:

$$
\begin{aligned}
& R_{\text {Mortality, },} ; \\
& R_{\text {RoadFatality, } ;} ; \\
& R_{\text {PersonalEmission, },} ; \\
& R_{\text {TransportEmission, },} \cdot
\end{aligned}
$$

Mortality described by personal safety was measured as mortality/inhabitants in each country in each year between 2000 and 2009. Road fatality described by road safety was measured as fatalities/motorised vehicles in each country in each year between 2000 and 2009. Personal emission was measured as country specific $\mathrm{CO}_{2}$ emission/inhabitants in each country in each year between 2000 and 2009. Road transport-related $\mathrm{CO}_{2}$ emission was measured as road transport-related $\mathrm{CO}_{2}$ emission/motorised vehicles in each country in each year between 2000 and 2009.

Basically in this paper not only the time series were analysed but a time independent cluster analysis was done. The clusters are separated based on grouping objects of similar kind into respective categories. Two time-independent hyper-function were created based on their time synchronity:

$$
\begin{aligned}
& f_{1}\left(R_{\text {Mortality }, t} ; R_{\text {RoadFatality, } t}\right) ; \\
& f_{2}\left(R_{\text {PersonalEmission, },} ; R_{\text {TransportEmission, }, t}\right) .
\end{aligned}
$$

Both of them can be simplified:

$$
\begin{aligned}
& f_{1}\left(R_{\text {Mortality }} ; R_{\text {RoadFatality }}\right) ; \\
& f_{2}\left(R_{\text {PersonalEmission }} ; R_{\text {TransportEmission }}\right) .
\end{aligned}
$$

This simplified functions can be visualised as Cartesian coordinates on Euclidean plane as Descartes coordinate system. These could be a solid basis of cluster analysis. Cluster analysis is used to reveal similarities. The similarities are defined as a small distance between entities by a property. In this case the distance was measured as Chebychev's distance. This distance measure is appropriate in cases when two objects are defined as 'different' if they are different on any one of the dimensions. The Chebychev's distance is computed as:

$$
\operatorname{distance}(x, y)=\max \left|x_{i}-y_{i}\right| .
$$

In these analysis 27 countries in 3 times (2000, 2005 and 2009) by two properties (fatality rate and mortality rate) as total 81 cases were visualised and investigated.

Not only were the countries compared to each other but the development tendency of each country as well in time. Based on these parameters the countries were grouped based on their Chebychev's distance. As the author proved the tendencies described in the international literature, further on the paper focuses on the environmental emission. The main research question was if the same tendencies can be found in case of environmental protection in road transport.
Further on dynamics of changes also been investigated based on Eq. (2) by having the differences of 2009 and 2000 status:

$$
\begin{aligned}
& f_{1}\left[\left(R_{\text {Mortality,2009; }} ; R_{\text {RoadFatality,2009 }}\right)-\right. \\
& \left(R_{\text {Mortality,2000; }} R_{\text {RoadFatality,2000 }}\right) ; \\
& f_{2}\left[\left(R_{\text {PersonalEmission,2009; }} ; R_{\text {TransportEmission,2009 }}\right)-\right. \\
& \left.\left(R_{\text {PersonalEmission,2000; }} R_{\text {TransportEmission,2000 }}\right)\right] .
\end{aligned}
$$

\subsection{Road Transport Safety}

Just to rank countries based on one of the rates (fatal accidents per road length or fatal accidents per population) is not the best approach, since the rates are depending - among others - on the level of motorization. Comparisons without taking into account the differences in the level of motorization can be misleading, therefore the motorization level was represented by PCU (Passenger Car Unit) and the road safety situation by fatal accidents per PCU. Having seen the Fig. 1, it can be stated, that the level of motorization has a decisive role in the level of road safety. Of course a lot of other factors have influence on the road safety level as well, but one of the most important influencing factors is the level of motorization.

The analysis of time series of road fatal accidents (Fig. 1) shows that significant improvement has been done all over in Europe and the number of fatal road accidents has been decreased significantly over time due to the strict EU road transport active and passive safety regulations and directives. Huge effort and enormous money was put behind this development.

\subsection{Road Transport Emission}

In this paper, emission is considered as $\mathrm{CO}_{2}$ emission as it is independent from the burning technology and can be a good statistical basis of comparison. Changes since 2000 concerning sustainable transport show a rather mixed picture. There is only minor progress in decoupling transport volumes and transport energy consumption from economic development. Changes in the modal split and transport volumes seem, in general, to be more favourable for passenger transport than for freight transport. Despite a short-lived increase in the share of investments in infrastructure for environmental friendly modes, such as walking, rail and ports, during the early years of the decade, the pattern of expenditure has returned to favouring road (Moeinaddini et al. 2012). While road accident fatalities have been much reduced, faster progress will be needed to achieve the objective of halving road fatalities between 2000 and 2010. Although greenhouse gas emissions from transport have continued to increase at an unfavourable rate and $\mathrm{CO}_{2}$ emissions from new passenger cars remain far from their target. As it can be seen from Fig. 2, significant development has been reached from 2005 to 2009 in the European area. It can be also stated, that the level of motorization has a decisive role in the level of road transport emission. Of course, lots of other factors have influence on the road transport emission as well, but one 


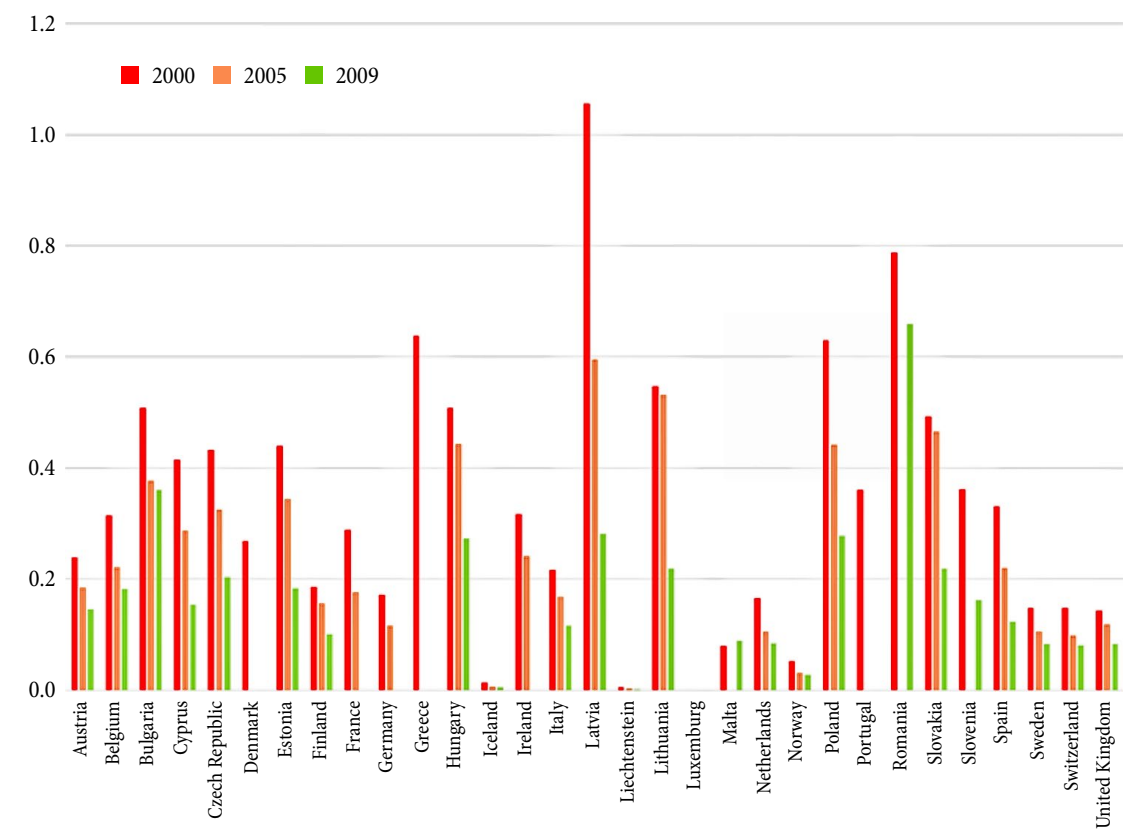

Fig. 1. Time series of fatal road accidents per capita ratio by countries (please note that only 2000, 2005 and 2009 were visualized in order to keep the resolution of figure)

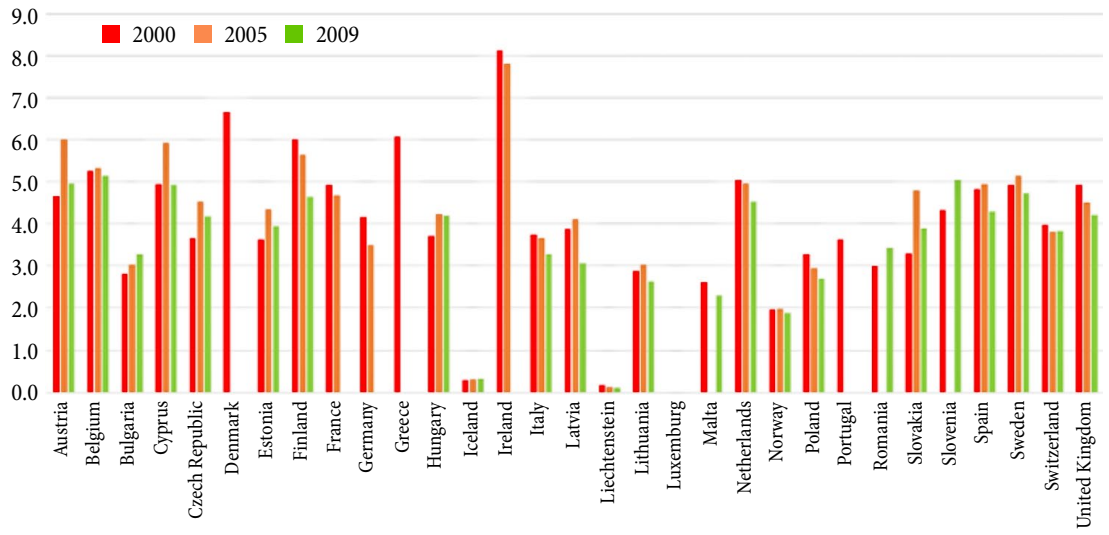

Fig. 2. Time series of $\mathrm{CO}_{2}$ emission per PCU by countries (please note that only 2000, 2005 and 2009 were visualized in order to keep the resolution of figure)

of the most important influencing factors is the level of motorization.

In presented analysis 27 countries in 3 times (2000, 2005 and 2009) by two properties (fatality rate and mortality rate) as total 81 cases were visualised and investigated.

Fig. 2 shows that significant efforts has been done all over in Europe and but the emitted $\mathrm{CO}_{2}$ per PCU has not been decreased significantly. In some case, even increase was experienced.

\section{Results - Comparative Socio-Economic Analysis}

\subsection{Road Transport Safety}

Nowadays only the number of road fatalities is appropriate for international comparison of road transport safety situation. The same, so-called '30-day definition' is used all over Europe (Papadimitriou et al. 2013). Statistical rates of fatality and mortality is needed in or- der to be able to filter out the cross-correlated factors. Theoretically the best exposure data is the number of vehicle-kilometres, the least appropriate is the number of population. The 'second best' exposure data is the vehicle fleet. For complex analysis fatality and mortality rates need to be distinguished. Mortality rate is the number of fatalities compared to the population, while fatality rate is the number of fatalities compared to level of motorisation. The mortality rate is more connected to socio-economical parameters while fatality rate is more connected to techno-economical parameters. So further analysis was done with the mortality and the fatality rates separated. There is a possibility for the common application of the two indicators as well, the so-called Trinca's model (Trinca et al. 1988).

The common application of these two indicators makes a more detailed comparison and ranking possible (Jankowska et al. 2014; Török et al. 2015). According to the international literature (Elvik 2010; Commandeur 
et al. 2013; Yannis et al. 2014) the whole process can be described as follows, at early stage of development road safety could increase with the lower of fatality rate (E' to $\mathrm{E}$ point) due to the increased number of vehicles. After that as the road safety situation get better due to the increasing economical activity mortality rate sadly increases ( $\mathrm{E}$ to $\mathrm{D}$ point). At the final stage of development both fatality and mortality rate would decrease (D to A point). In Fig. 4. the EU27 countries were shown in 2000, 2005 and 2009 based on Eq. (2). These dots really evaluate the tendency of the Trinca's model. Furthermore, the dynamics of the improvement can also be noticed.

The cluster analysis of Eq. (3) revealed with help of Eq. (4) a significant difference between in case of mortality and fatality rate in the CORE (Core Countries -

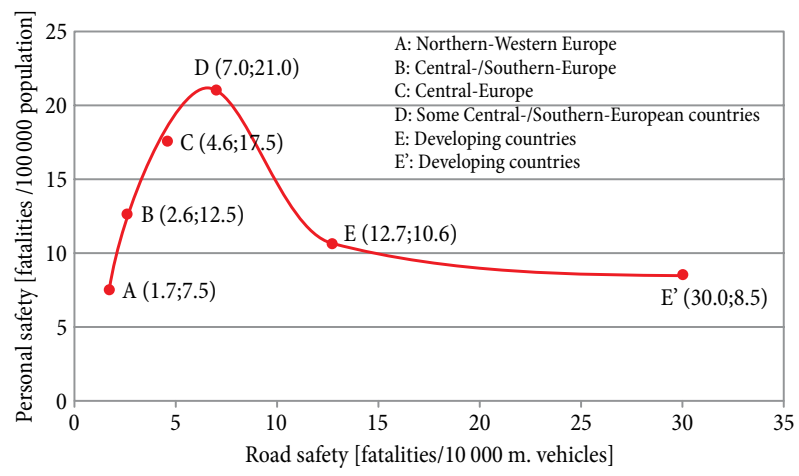

Fig. 3. Relationship between personal safety and road safety (theoretical model) (source: Trinca et al. 1988)
EU15) and in the NAS (Newly Associated Countries) countries. Therefore the analysis of change between 2000 and 2009 were visualized separately in both cases based on Eq. (5) (Fig. 5):

As it can be seen from Fig. 5, the CORE EU countries have made significantly bigger development compared to NAS EU countries in road transport safety sector.

\subsection{Road Transport Emission}

Between 2000 and 2009 growth rates of transport greenhouse gas emissions in the EU27 slowed down compared to the period 1990-2000. Road dominates with $94 \%$ of total transport greenhouse gas emissions in 2009 (Mitsakis et al. 2014). One of the reasons for the increase in greenhouse gas emissions are the $\mathrm{CO}_{2}$ emissions of new passenger cars which remain significantly above the path necessary to reach EU targets (Szendrö, Török 2014). Theoretically, the best exposure data is the number of vehicle-kilometres, the least appropriate is the number of population. The 'second best' exposure data is the vehicle fleet (Szendro et al. 2012). For complex analysis transport-related emission and personal emission need to be distinguished to be able to compare with fatality and mortality rate. Personal emission rate is the mass of emitted $\mathrm{CO}_{2}$ compared to the population, while transport-related emission rate is the mass of emitted $\mathrm{CO}_{2}$ compared to the level of motorisation. The personal emission rate is more connected to socioeconomical parameters while transport-related emission

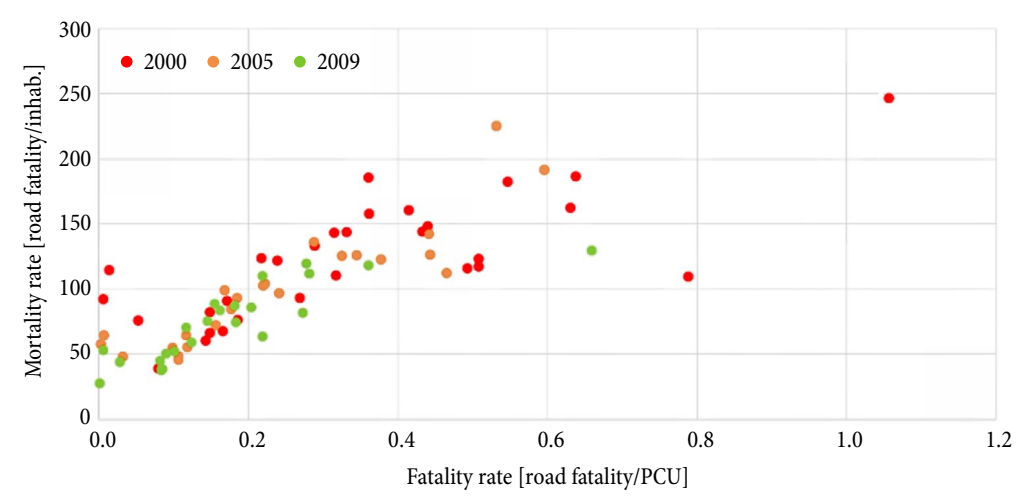

Fig. 4. Statistical development of mortality and fatality rates (please note that only 2000, 2005 and 2009 were visualized in order to keep the resolution of figure)

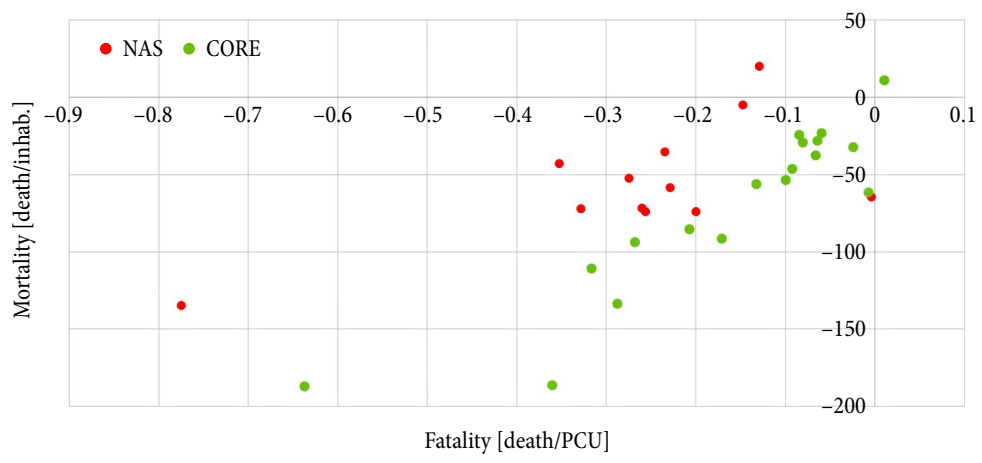

Fig. 5. Dynamics of mortality and fatality rates (please note that only 2000, 2005 and 2009 were visualized in order to keep the resolution of figure) 
rate is more connected to techno-economical parameters (Andrejszki et al. 2014). The main research question is if the tendency behind road safety (Trinca's theory connection between personal and road safety) can be extended to road transport-related emission. The common application of these two indicators makes a more detailed comparison and ranking possible. According to the described theory the whole process can be described as follows, at early stage of development road transport-related emission ratio could increase with the lower of transport emission rate (E' to E point at Fig. 3). After that as the road-emission situation gets better due to the increasing economical activity, personal emission rate sadly increases (E to $\mathrm{D}$ point). At the final stage of development both transport-related and personal emission rate would decrease ( $\mathrm{D}$ to $\mathrm{A}$ point). To evaluate the theory, EU27 countries were analysed in 2000, 2005 and 2009 based on Eq. (2) (Fig. 6).

The cluster analysis of Eq. (3) has been done with the help of Eq. (4) in order to investigate the spatial distribution of developments. For comparative purposes the same segregation to NAS and CORE countries were done as previously. In addition, the dynamics based in Eq. (5) has been investigated and visualised.

As it can be seen from Fig. 7, the NAS EU countries have different development path compare to CORE EU countries in terms of $\mathrm{CO}_{2}$ emission as well. The difference is clearly visible. The CORE countries lowered their personal and transport-related emission meanwhile the NAS group had some minor increase in emission in the investigated period. That means although the Trinca's model was evaluated also in this case, the tendency shows some minor deviation in case of NAS countries.

\section{Conclusions}

Trinca's model that describes the connection between mortality rate, which is more connected to socio-economical parameters and fatality rate, which is more connected to techno-economical parameters. According to Trinca's model the increase of economic activity will lead to decrease in decrease in mortality and fatality as well.

In this paper author used the same model to investigate personal emission, which is more connected to socio-economical parameters and transport-related emission, which is more connected to techno-economical parameters. The phenomena that describes Trinca's model is the economical development that can be revealed in case of emission as well. Further on the spatial selection exposed some spatial differences. In case of curbing the emissions of the transport sector it is needed to acknowledge there are existing regional differences in the current status. The caution for social and economical differences need to be considered and require further analysis. As a conclusion it can be stated that the Trinca's model could be justified in case of EU27 for emission. However, separating to NAS and CORE countries the results gave us a detailed picture. The CORE countries lowered their personal and transport-related emission meanwhile the NAS group had some minor increase in emission in the investigated period.

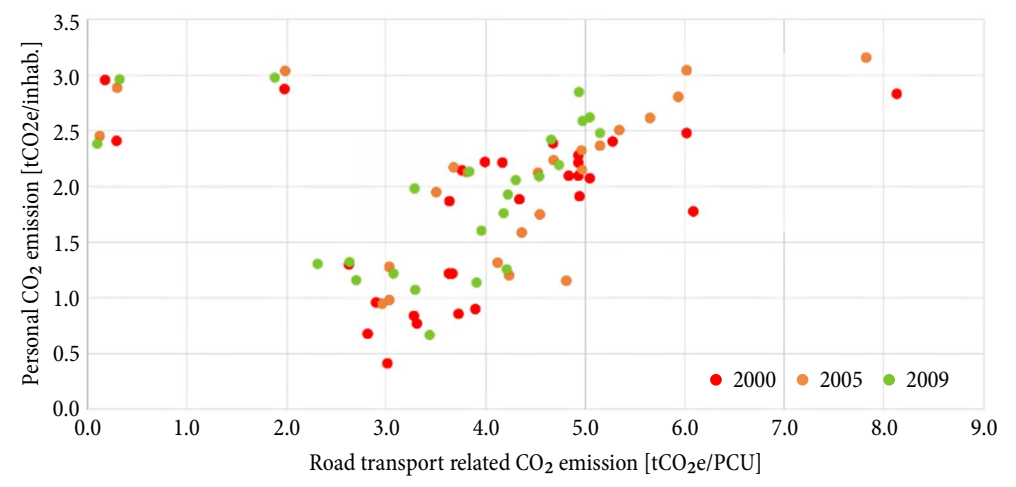

Fig. 6. Statistical development personal and transport-related emission rates (please note that only 2000, 2005 and 2009 were visualized in order to keep the resolution of figure)

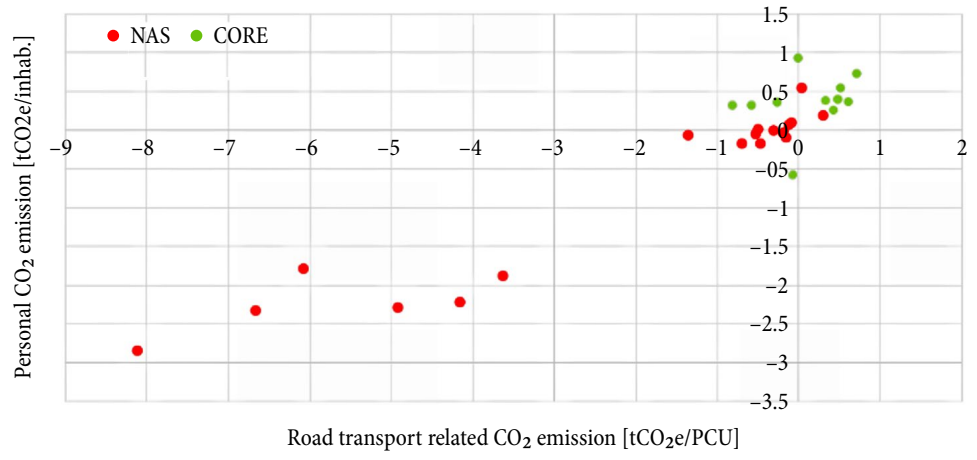

Fig. 7. Dynamics of personal and transport-related emission rates (please note that only 2000, 2005 and 2009 were visualized in order to keep the resolution of figure) 


\section{References}

Andrejszki, T.; Gangonells, M.; Molnar, E.; Török, Á. 2014. ForFITS: a new help in transport decision making for a sustainable future, Periodica Polytechnica Transportation Engineering 42(2): 119-124. http://dx.doi.org/10.3311/PPtr.7442

Bhalla, K.; Ezzati, M.; Mahal, A.; Salomon, J.; Reich, M. 2007. A risk-based method for modeling traffic fatalities, Risk Analysis 27(1): 125-136. http://dx.doi.org/10.1111/j.1539-6924.2006.00864.x

Commandeur, J. J. F.; Bijleveld, F. D.; Bergel-Hayat, R.; Antoniou, C.; Yannis, G.; Papadimitriou, E. 2013. On statistical inference in time series analysis of the evolution of road safety, Accident Analysis \& Prevention 60: 424-434. http://dx.doi.org/10.1016/j.aap.2012.11.006

Dumbaugh, E.; Rae, R. 2009. Safe urban form: revisiting the relationship between community design and traffic safety, Journal of the American Planning Association 75(3): 309329. http://dx.doi.org/10.1080/01944360902950349

Elvik, R. 2010. The stability of long-term trends in the number of traffic fatalities in a sample of highly motorised countries, Accident Analysis \& Prevention 42(1): 245-260. http://dx.doi.org/10.1016/j.aap.2009.08.002

Hilmola, O.-P. 2013. From bubble to sustainable economy in the Baltic States, Transport and Telecommunication 14(3): 237-249.

Jankowska, D.; Wacowska-Slezak, J.; Zukowska, J. 2014. Foreign visitors from Visegrad countries with regard to road safety in Poland, Periodica Polytechnica Transportation Engineering 42(1): 77-83. http://dx.doi.org/10.3311/PPtr.7250

Kenworthy, J.; Laube, F.; Newman, P.; Barter, P. 1997. Indicators of Transport Efficiency in 37 Global Cities: a Report for the World Bank. ARRB Group Limited. 40 p.

Mitsakis, E.; Papanikolaou, A.; Ayfadopoulou, G.; Salanova, J.; Doll, C.; Giannopoulos, G.; Zerefos, C. 2014. An integrated framework for linking climate change impacts to emergency adaptation strategies for transport networks, European Transport Research Review 6(2): 103-111. http://dx.doi.org/10.1007/s12544-013-0114-0

Moeinaddini, M.; Asadi-Shekari, Z.; Shah, M. Z. 2012. The effectiveness of private motorized trips indicators in reducing car usage, International Journal for Traffic and Transport Engineering 2(4): 347-358. http://dx.doi.org/10.7708/ijtte.2012.2(4).05

Papadimitriou, E.; Yannis, G.; Bijleveld, F.; Cardoso, J. L. 2013. Exposure data and risk indicators for safety performance assessment in Europe, Accident Analysis \& Prevention 60: 371-383. http://dx.doi.org/10.1016/j.aap.2013.04.040

Shen, Y.; Hermans, E.; Bao, Q.; Brijs, T.; Wets, G. 2013. Road safety development in Europe: a decade of changes (20012010), Accident Analysis \& Prevention 60: 85-94. http://dx.doi.org/10.1016/j.aap.2013.08.013

Szendro, G.; Csete, M.; Torok, A. 2012. Unbridgeable gap between transport policy and practice in Hungary, Journal of Environmental Engineering and Landscape Management 20(2): 104-109.

http://dx.doi.org/10.3846/16486897.2012.660881

Szendrő, G.; Török, A. 2014. Theoretical investigation of environmental development pathways in the road transport sector in the European Region, Transport 29(1): 12-17. http://dx.doi.org/10.3846/16484142.2014.893538
Török, Á.; Kiss, Á.; Szendrö, G. 2015. Introduction to the road safety situation in Hungary, Periodica Polytechnica Transportation Engineering 43(1): 22-26. http://dx.doi.org/10.3311/PPtr.7510

Trinca, G. W.; Johnston, I. R.; Campbell, B. J.; Haight, F. A.; Knight, P. R.; Mackay, G. M.; McLean, J.; Petrucelli, E. 1988. Reducing Traffic Injury - a Global Challenge. Royal Australasian College of Surgeons. $146 \mathrm{p}$.

Yannis, G.; Papadimitriou, E.; Folla, K. 2014. Effect of GDP changes on road traffic fatalities, Safety Science 63: 42-49. http://dx.doi.org/10.1016/j.ssci.2013.10.017 